\title{
Antifouling Properties of Zinc Nitrate in Seawater
}

\author{
M. J. Suriani, S. Ramlan, and W. B. Wan Nik
}

\begin{abstract}
This study aim to investigate the potential of antifouling properties of zinc nitrate for mild steel in sea water. Fourier Transform Spectroscopy Infrared (FTIR) analysis is to identify various functiona $I$ groups and unknown compounds present in the zinc nitrate that contribute to the antifouling properties. Screening test is conducted by using an Antifouling Crystal Violet Biofilm Assay method in order to prove the ability of the zinc nitrate to become an antifouling agent. Specimen used is mild steel A36 at dimension of $25 \mathrm{~mm} \times 25 \mathrm{~mm} \times$ $3 \mathrm{~mm}$. All specimens coated with zinc nitrate incorporated in acrylic varnish are immersed in sea water at Chendering Port about 50 days. Data were analyses by weight measurement method and scanning electron microscope (SEM). The weight measurement results shown as the amount of zinc nitrate increase, the higher antifouling rate. Zinc nitrate evidently proved the ability to inhibit the growth and the formation of biofilm of adhesive bacteria. It is significantly prevent the attachment of the biofouling organism.
\end{abstract}

Index Terms-Antifouling, biofouling, marine environment, zinc nitrate.

\section{INTRODUCTION}

Coastal water of the Chendering port, Terengganu has been widely used for the boat of fishermen to go to the sea. It also an industrial place where many boat landed at the side. The Chendering port is important to fishermen who not only unload their catch but also mooring their vessels. Due to the siltation of many of the river mouths in Terengganu, there have been an increasing number of fishermen using this port which is accessible all year around. Due to the situation, it is suitable for marine biofouling growth at the ship hull. So, the fishermen faced many problems in order to remove this marine biofouling.

The effect of marine environment on the boat hull is recognized primarily as biofouling. Antifouling is the process of removing or preventing accumulations of barnacles from forming [1]. The type and extent of fouling depend on the local environment, inorganic deposits and organisms; this varies significantly between medical, marine and industrial applications. In general, medical biofouling includes only the biofilm, whereas marine and industrial biofouling generally include a combination of biofilm, macrofouling and inorganic fouling [2]-[6]. As claimed by Chambers et al., [7], the use of antifouling coatings for protection from the marine environment has a long history. Antifouling is the most

Manuscript received November 30, 2015; revised March 30, 2016

M. J. Suriani and W. B. Wan Nik are with the School of Ocean Engineering, Universiti Malaysia, Terengganu, 21030 Kuala Terengganu, Terengganu, Malaysia (e-mail: surianimatjusohumt.edu.my, niksani@umt.edu.my).

S. Ramlan is with the Alumni of Maritime Technology, School of Ocean Engineering, Universiti Malaysia, Terengganu, 21030 Kuala Terengganu, Terengganu, Malaysia (e-mail: syazuwani1@gmail.com). common and important painting job carried out by coat owners. It is vital to protect the boat by using antifouling paint. Applying an antifouling paint will prevent the attachment of fouling organisms such as barnacles, weeds and slime to the hull. When this fouling organism is not preventing early, it can growth rapidly and causing serious problem. Therefore, prevention is much better than cure.

To prevent this, antifouling coatings are applied to the hulls. Antifouling paints contain biocides that repel fouling organisms when released at a controlled rate into the water adjacent to the hull. Antifouling coatings owe their behavior to the release of toxic substances to the marine environment. This leaching process produces a high concentration of antifouling compounds in the seawater film in close contact with the painted surface, thereby repelling or killing fouling organisms when they try to attach to the surface. The performance of an antifouling paint is dependent on the biocide and the way the biocide is leached from the film [8]. However, some of antifouling were forbidden or restricted in their use by International Maritime Organization (IMO) because they contain heavy metals which may be accumulated in the environment. Such as tributyltin (TBT) oxide and copper are banned from used because it slower the production of microorganisms. Then to solve the issue, protective organic coatings can offer these functions [9]-[14] and consequently are largely used in the shipping industry to increase the working life of systems and improve its reliability.

Nitrate is one of the most important elements in marine chemistry; at least as far as sea life is concerned [15]. Marine algae support virtually all life in the oceans but in order to flourish, they require lots of sunlight and nutrients especially nitrate. Therefore, a new research on antifouling is currently being committed to search for non-toxic or less toxic antifouling alternatives. In this study, an acrylic varnish coating was modified with zinc nitrate and the characteristic of this new modified coating was examined.

\section{Methodology}

\section{A. Determination of Seawater Salinity}

Salinity is the dissolved salt content or "saltiness" of a body of water. Salinity of seawater can be measured in parts per thousand or (ppt) which is approximately grams of salt per kilogram of solution. Average ocean salinity is $35 \mathrm{ppt}$ as compared with freshwater salinity of about .5ppt and less. It is probably worth mentioning that water is not considered fresh water (lower ppt level) and not considered ocean or seawater (high ppt) is referred to as "brackish water" (5 ppt to about 18 ppt).

Seawater samples were collected from Chendering Port. Salinity was determined in situ and then the salinity was 
analyzed at laboratory. Parameters such as water temperature, salinity and $\mathrm{pH}$ recorded and observed.

\section{B. Specimens Preparation}

Firstly, 20 plates of mild steel grades A36 with $25 \mathrm{~mm} \times$ $25 \mathrm{~mm} \times 3 \mathrm{~mm}$ dimension was prepared. The specimens were drilled to make two holes at the corner of the specimens. After that, power tool cleaning method using copper brush was used to polish the surface of mild steel. The specimens were polished by using abrasive paper grade 600,800 , and 1200 to smooth the surface. After polishing process, the specimens then were clean with distilled water, then acetone and rinse with distilled water. After that, the specimens were dried on room temperature before transfer to the desiccators.

The specimens were taken from desiccator and clean using a thinner in order to remove contaminant on the surface of specimen. After that, zinc nitrate was incorporated in acrylic varnish and then the mild steel was coated with this new modified coating. Then, the specimens were placed in the oven to dry. The coatings were formulated as shown in Table I.

TABLE I: FORMULATION OF ACRYLIC VARNISH WITH ZINC NITRATE

\begin{tabular}{llllll}
\hline $\begin{array}{l}\text { Types of } \\
\text { coating } \\
(\mathrm{g})\end{array}$ & $\begin{array}{l}\mathrm{Zn}(\mathrm{N}) \\
(\mathrm{g})\end{array}$ & $\begin{array}{l}\text { Quantity } \\
\text { of mild } \\
\text { steel }\end{array}$ & $\begin{array}{l}\text { Epoxy } \\
\text { base } \\
(\mathrm{ml})\end{array}$ & $\begin{array}{l}\text { Hardener } \\
(\mathrm{ml})\end{array}$ & $\begin{array}{l}\text { Thinner } \\
(\mathrm{ml})\end{array}$ \\
\hline $\begin{array}{l}\text { Bare } \\
\text { (control) }\end{array}$ & - & 5 & 100 & 25 & 150 \\
\hline Paint 1 & 2 & 5 & 100 & 25 & 150 \\
\hline Paint 2 & 4 & 5 & 100 & 25 & 150 \\
\hline Paint 3 & 6 & 5 & 100 & 25 & 150 \\
\hline
\end{tabular}

Before immersion, the specimens were weighed by using analytical weight. Then, the specimens were hung at the cage and fully immersed in the seawater for 50 days.

\section{Antifouling Crystal Violet Anti-Biofilm Assay}

This project focuses to study anti-biofilm formation by the model organisms Pseudomonas Aeruginosa, Bacillus cereus and Salmonella $s p$ as the target bacteria. The target bacteria are marine bacteria that grow in sea water. At the same time it is known as first microfouler that attack the submerged surfaces of manmade structures. In this experiment, zinc nitrate was used as an inhibitor against target bacteria.

Antifouling Crystal Violet Anti-Biofilm Assay is divided into two method that were screening and dilution method. Firstly, the screening test was done in order to screening the effectiveness of antifouling potential to zinc nitrate. After that zinc nitrate was subjected to dilution method to know its inhibition concentration at $50 \%$ (IC50). The principal of the Bioassay method is the colorimetric assay of biofilms were stained with crystal violet and followed by the removal of unbound staining.

Firstly, Muller Himpton Broth and Muller Himpton Agar were prepared. After that, preparation of target bacteria was done. The Optical Density (OD) of bacteria liquid culture was determined. The concentration of culturing bacteria must less than 0.2. Prepared bacteria suspension, Muller Himpton Broth (MHB) and pipetting liquid culture bacteria was pipetting inside 96 well of microtiter plate as shown in Fig. 3. Then, the plate was transfer into incubator to allow the growth of biofilms.
After 24 -h incubation at $37^{\circ} \mathrm{C}$, the medium was gently removed and the microtiter plate wells were washed three times with $200 \mu \mathrm{l}$ per well of distilled water using a multichannel pipette and allowed to dry for 15 minutes. The microtiter plate wells were stained with $200 \mu \mathrm{l}$ of $0.4 \%$ crystal violet for $20 \mathrm{~min}$ at room temperature. The unbound crystal violet stain was removed and the wells were washed gently three times with $200 \mu \mathrm{l}$ of distilled water without touching the well's wall. The wells were air-dried for 15 minutes and the crystal violet in each well was solubilized by adding $200 \mu \mathrm{l}$ of $90 \%$ alcohol and incubated at room temperature for 10 minutes in shaking. The motion plate was read at $595 \mathrm{~nm}$ using UV-Vis Spectrophotometer. The data was analyse using (1).

$$
\begin{aligned}
& \text { Percentage Inhibition }(\%)= \\
& \qquad \frac{\text { ODNegativeControl-ODSample }}{\text { ODNegativeControl }} \times 100 \%
\end{aligned}
$$

\section{Fourier Transform Infrared Spectroscopy (FTIR)}

An acrylic varnish coating was modified with zinc nitrate and the characteristic of this new modified coating are subjected to the FTIR test in order to know its functional group.

\section{E. Weight Measurement}

Before the specimens were immersed in seawater, the initial weight was weighed by using analytical weighting. After 50 days of immersion, the cage was taken out from seawater and the specimens were weighed in order to obtain the final weight.

The calculation percentage of additional of weight has been determined to represent the fouling rate and efficiencies of the inhibitor based on (2). The equation is used in order to obtain percentage of additional weight.

Percentage Additional of Weight $(\%)=$

$$
\frac{\text { Finalweight }- \text { Initialweight }}{\text { Totalweight }} \times 100 \%
$$

\section{F. Scanning Electron Miscroscopy (SEM)}

SEM is used in this study to find the morphology profile of mild steel in the presence and absence of biofouling and other organisms. Then the morphology of the surface was analyzed. Surface measurement is done after the metal is immersed for 50 days.

\section{RESULT AND DISCUSSION}

\section{A. Water Salinity}

Chendering Port was chosen as a sampling place because it is an industrial area where many fishermen boat landed. The $\mathrm{pH}$ is in the good range for fouling organism growth. The suitable condition for fouling organisms' growth ranges of $\mathrm{pH}$ is 8.2 to 8.3 . The range of salinity is from 32 to $35 \mathrm{ppt}$ and temperature is higher than $20{ }^{\circ} \mathrm{C}$. Zinc can enter the aquatic environment from a number of sources including industrial 
discharges, sewage effluent and runoff [16].

TABLE II: PHYSICAL PARAMETERS SEAWATER

\begin{tabular}{ccccc}
\hline $\mathrm{pH}$ & $\begin{array}{c}\mathrm{DO} \\
\left(\mathrm{mgL}^{-1}\right)\end{array}$ & $\begin{array}{c}\text { Temperature } \\
\left({ }^{\circ} \mathrm{C}\right)\end{array}$ & Salinity & Turbidity(NTU) \\
\hline 7.32 & 6.58 & 30.7 & 32.7 & 25.0
\end{tabular}

The physical Chendering seawater is determined and reported in Table II. Water samples analyzed are near neutral (pH 7.93). DO is $6.58 \mathrm{mgL}^{-1}$ with temperature $30.7^{\circ} \mathrm{C}$. The salinity is $32.7 \mathrm{ppt}$ and turbidity is $25.0 \mathrm{NTU}$. It can be seen that all the elements show relatively near to the suitable condition of fouling growth. The influence of various sea water characteristics such as salinity, temperature, $\mathrm{pH}$, dissolved salts and oxygen concentration on the fouling of immersed solid surfaces is also well known [17]. Therefore, sea water at Chendering port is suitable place for immersion test due to domestic or industrial effluents.

\section{B. Fourier Transform Infrared Spectroscopy (FTIR)}

A FTIR spectra graph shown in Fig. 1. was obtained after the test. The result show that the functional groups that abundantly present in zinc nitrate which is hydrozincite structure.

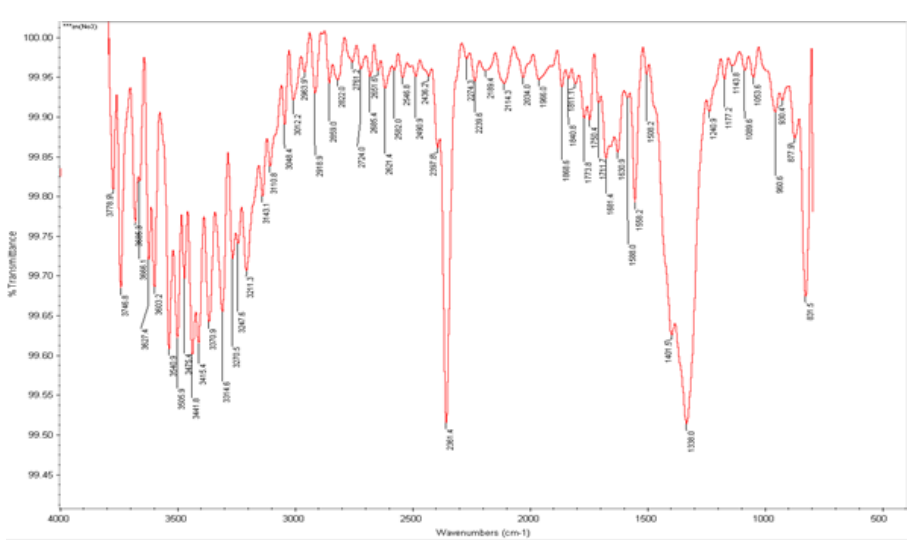

Fig. 1. FTIR spectra graph for new formulation paint of zinc nitrate.

Based on the graph, it shown the abundant elements that contain in zinc nitrate were phenolic bonding, $\mathrm{O}-\mathrm{H}$ stretching frequency at $3627 \mathrm{~cm}-1$, nitro bonding, N-O stretching frequency at $1338.0 \mathrm{~cm}-1$, at $2361.4 \mathrm{~cm}-1$ indicating $\mathrm{C}-\mathrm{C}, \mathrm{C} \equiv \mathrm{N}$ (Nitriles) and at $1630.9 \mathrm{~cm}-1$ indicating nitrate $2361.4 \mathrm{~cm}-1$ was observed representing the presence of $-\mathrm{C}-\mathrm{C}$ stretching for primary alcohols [18], may due to the microbial oxidation of used oil.

Besides that, $1630.9 \mathrm{~cm}-1$ indicating nitrate represent the external water molecules. It is the conjugate base of nitric acid, consisting of one central nitrogen atom surrounded by three identical oxygen atoms on a trigonal planar arrangement. The nitrate ion carries a formal charge of negative one, where each Oxygen carries a $-2 / 3$ charge whereas the nitrogen carries $a+1$ charge, and is commonly used as an example of resonance. Like the isoelectronic carbonate ion, the nitrate ion can be represented by resonance structures. Almost all inorganic nitrate salts are soluble in water at standard temperature and pressure. Fig. 2 shows molecular structure for zinc nitrate.

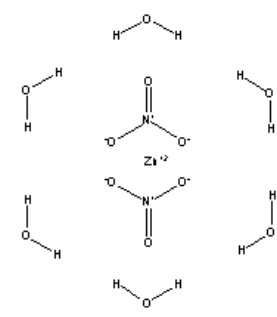

Fig. 2. Molecular structure for zinc nitrate.

The N-O is nitro compound which classified on the nitro functional group stretch at $1338 \mathrm{~cm}-1$. Nitro compounds are organic compounds that contain one or more nitro functional groups. After that, at peak $3627.4 \mathrm{~cm}-1$ represent phenolic bonding, $\mathrm{O}-\mathrm{H}$ stretch free hydroxyl alcohol, phenols. There is an interaction between delocalized electrons in the benzene ring and one of the lone pairs on the oxygen atom. This has an important effect on both the properties of the ring and of the $\mathrm{O}-\mathrm{H}$ group.

\section{Antifouling Crystal Violet Anti-Biofilm Assay}

The bacteria used were Pseudomonas aeruginosa, Bacillus cereus and Salmonella $s p$ where these bacteria were pipette in triplex order of $200 \mu 196$ well of microtiter plate. Table III shows the reading of target bacteria from spectrofotometer machine. The ( $\mathrm{IC}_{50}$ ) value for crystal violet assay against for target bacteria are recorded in Table IV. The equation (3) shows the formula of inhibition efficiency concentration.

Inhibition Efficiency (IE) =

$$
\frac{\text { ODNegativeControl-ODSample }}{\text { ODNegativeControl }} \times 100 \%
$$

TABLE III: OPTICAL DENSITY FOR DILUTION TEST

\begin{tabular}{cccc}
\hline $\begin{array}{c}\text { Target } \\
\text { Bacteria }\end{array}$ & \multicolumn{3}{c}{ Optical Density (OD) } \\
\hline $\begin{array}{c}\text { Concentratio } \\
\mathrm{n} \text { of } \mathrm{Zn}\left(\mathrm{NO}_{3}\right)_{2}\end{array}$ & $\begin{array}{c}\text { Pseudomonas } \\
\text { aeruginosa }\end{array}$ & $\begin{array}{c}\text { Bacillus } \\
\text { cereus }\end{array}$ & $\begin{array}{c}\text { Salmonella } \\
\mathrm{sp}\end{array}$ \\
\hline 0 & 1.1667 & 0.977618 & 1.12449 \\
\hline 5 & 0.630281 & 0.682731 & 0.711791 \\
\hline 10 & 0.582183 & 0.580289 & 0.584949 \\
\hline 15 & 0.540593 & 0.523008 & 0.514994 \\
\hline 20 & 0.752498 & 1.0218 & 0.965282 \\
\hline 25 & 0.988261 & 1.05081 & 0.827052 \\
\hline 30 & 1.04426 & 0.829932 & 0.714288 \\
\hline $\begin{array}{c}\text { Negative } \\
\text { Control }\end{array}$ & 1.40505 & 1.22053 & 1.16292 \\
\hline
\end{tabular}

TABLE IV: INHIBITION EFFICIENCY FOR DILUTION TEST Target Optical Density (OD) Bacteria

\begin{tabular}{cccc}
\hline $\begin{array}{c}\text { Concentratio } \\
\mathrm{n} \text { of } \mathrm{Zn}\left(\mathrm{NO}_{3}\right)_{2}\end{array}$ & $\begin{array}{c}\text { Pseudomonas } \\
\text { aeruginosa }\end{array}$ & $\begin{array}{c}\text { Bacillus } \\
\text { cereus }\end{array}$ & $\begin{array}{c}\text { Salmonella } \\
\mathrm{sp}\end{array}$ \\
\hline 0 & 1.1667 & 0.977618 & 1.12449 \\
\hline 5 & 0.630281 & 0.682731 & 0.711791 \\
\hline 10 & 0.582183 & 0.580289 & 0.584949 \\
\hline 15 & 0.540593 & 0.523008 & 0.514994 \\
\hline 20 & 0.752498 & 1.0218 & 0.965282 \\
\hline 25 & 0.988261 & 1.05081 & 0.827052 \\
\hline 30 & 1.04426 & 0.829932 & 0.714288 \\
\hline $\begin{array}{c}\text { Negative } \\
\text { Control }\end{array}$ & 1.40505 & 1.22053 & 1.16292 \\
\hline
\end{tabular}




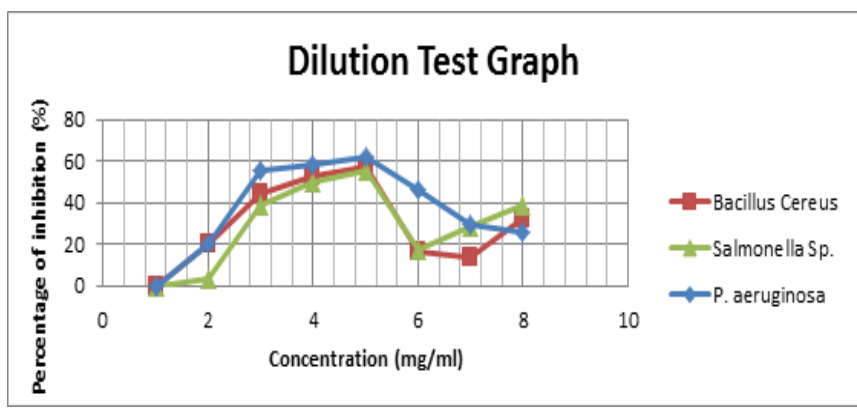

Fig. 3. Graph dilution test for antifouling crystal violet anti-biofilm assay.

From the Fig. 3, zinc nitrate have higher antifouling potential toward Pseudomonas aeruginosa compare to Bacillus cereus and Salmonella Sp. The optimum concentration (IC50) for Pseudomonas aeruginosa was 2.8 $\mathrm{mg} / \mathrm{ml}$ whereas for Bacillus Cereus and Salmonella Sp. was $3.6 \mathrm{mg} / \mathrm{ml}$ and $4.0 \mathrm{mg} / \mathrm{ml}$. As the conclusion, it has been evidently proved the amount of zinc nitrate should have in paint for prevention the attachment of fouling was $2.8 \mathrm{~g}$ for every $100 \mathrm{ml}$.

TABLE V: OPTIMUM INHIBITION CONCENTRATION OF ZINC NITRATE AT $50 \%$

\begin{tabular}{cc}
\hline Target Bacteria & $50 \%$ \\
\hline P. Aeruginosa & IC $_{\mathbf{5 0}}(\mathbf{m g} / \mathbf{m l})$ \\
\hline Bacillus Cereus & 2.8 \\
\hline Salmonella Sp. & 3.6 \\
\hline
\end{tabular}

\section{Weight Measurements}

The calculation percentage of additional of weight has been determined to represent the fouling rate and efficiencies of the zinc nitrate based on (4).

The data was combined to compare the percentage additional of weight. A36 have a high percentage of additional weight due to the high reaction of the metal's coating with fouling organism. Seawater is a habitat for fouling organism. When the metals were immersed in the seawater, the zinc nitrate particle will inhibit the attachment of fouling on the surface of metal. The highest percentage of weight gain contributes to higher fouling rate

$$
\begin{aligned}
& \text { Percentage Additional of Weight }= \\
& \qquad \frac{\text { Finalweight }- \text { Initialweight }}{\text { Totalweight }} \times 100 \%
\end{aligned}
$$

Table $\mathrm{V}$ shows the data of the additional of weight percentage for each sample. The result indicates effective action of zinc nitrate to antifouling in sea water. The total weight initial and final values for bare mild steel is higher compared to paint 1 , paint 2 and paint 3 . This indicates that many attachments of marine organisms at plates bare mild steel. Paint 3 showed lower in weight gain because there is much zinc nitrate coating at the plates and can avoid fouling's attachment. The reading of weight gain of each plate is not actually had a big different because zinc nitrate amount is not much greater.

Data obtained from weight measurement calculation was analyzed using graphical method. The calculation percentage of additional weight has been determined to represent the fouling rate. The percentage of additional of weight versus parameters was plotted as shown in Fig. 4. Weight of measurement is one simple measurement in determine the fouling rate of the plates. All the data was combined to compare the percentage of additional weight.

\begin{tabular}{|c|c|c|c|c|}
\hline Paint & $\begin{array}{c}\text { Initial } \\
\text { Weight (g) }\end{array}$ & $\begin{array}{c}\text { Final } \\
\text { Weight (g) }\end{array}$ & $\begin{array}{c}\text { Total } \\
\text { Weight }(\mathrm{g})\end{array}$ & $\begin{array}{l}\text { Additional of } \\
\text { Weight (\%) }\end{array}$ \\
\hline \multirow{5}{*}{$\begin{array}{l}\text { BARE } \\
\text { (control) }\end{array}$} & 18.247 & 20.781 & 39.028 & 0.065 \\
\hline & 16.622 & 19.183 & 35.805 & 0.071 \\
\hline & 18.057 & 20.517 & 38.574 & 0.064 \\
\hline & 17.630 & 20.279 & 37.909 & 0.069 \\
\hline & 17.767 & 20.454 & 38.221 & 0.070 \\
\hline \multirow{5}{*}{ Paint 1} & 17.672 & 18.835 & 36.507 & 0.032 \\
\hline & 18.206 & 19.512 & 37.718 & 0.035 \\
\hline & 18.148 & 19.244 & 37.392 & 0.029 \\
\hline & 17.179 & 18.393 & 35.572 & 0.034 \\
\hline & 18.023 & 19.126 & 37.149 & 0.030 \\
\hline \multirow{5}{*}{ Paint 2} & 18.467 & 19.471 & 37.938 & 0.026 \\
\hline & 18.052 & 18.757 & 36.809 & 0.019 \\
\hline & 17.861 & 18.883 & 36.644 & 0.025 \\
\hline & 18.097 & 18.815 & 36.912 & 0.019 \\
\hline & 17.766 & 18.320 & 36.086 & 0.015 \\
\hline \multirow{5}{*}{ Paint 3} & 17.532 & 18.016 & 35.548 & 0.014 \\
\hline & 17.973 & 18.501 & 36.474 & 0.014 \\
\hline & 17.268 & 17.324 & 34.592 & 0.002 \\
\hline & 18.119 & 18.335 & 36.454 & 0.005 \\
\hline & 17.525 & 17.726 & 35.251 & 0.005 \\
\hline
\end{tabular}

TABLE VI: OPTIMUM INHIBITION CONCENTRATION OF ZINC NITRATE AT

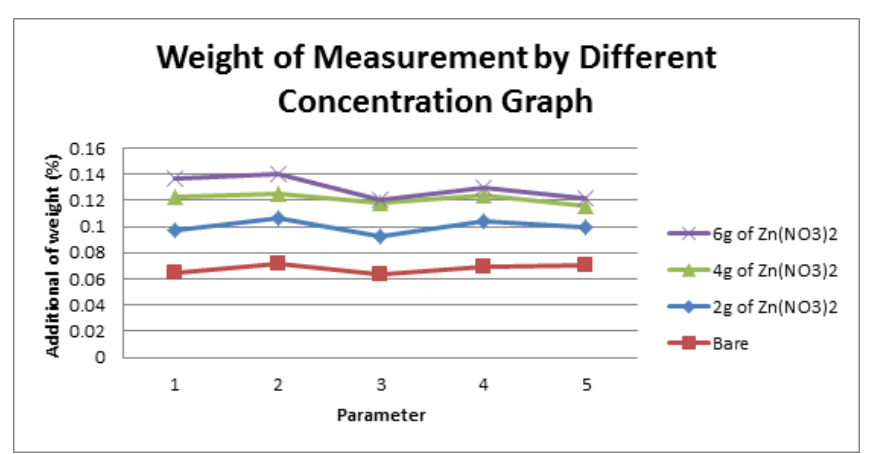

Fig. 4. Graph percentages additional of weight.

The graph showed the decreasing additional of weight percentage because an attachment of fouling organisms. The highest percentage of weight gain contributes to higher fouling rate. From Fig. 5, bare mild steel shows the highest increasing of weight because it is a control and also it does not coat anything of zinc nitrate. Then, the decreasing of weight is followed by paint 1 , paint 2 and paint 3 . Fouling organism consume much time to attach at the surface of specimens such as bare mild steel because of the corrosion process occur when metal immersed in sea water. From the graph, paint 3 has the higher quantity of zinc nitrate but has a lower increasing in weight. This can proves that the higher zinc nitrate used the higher antifouling rate. 


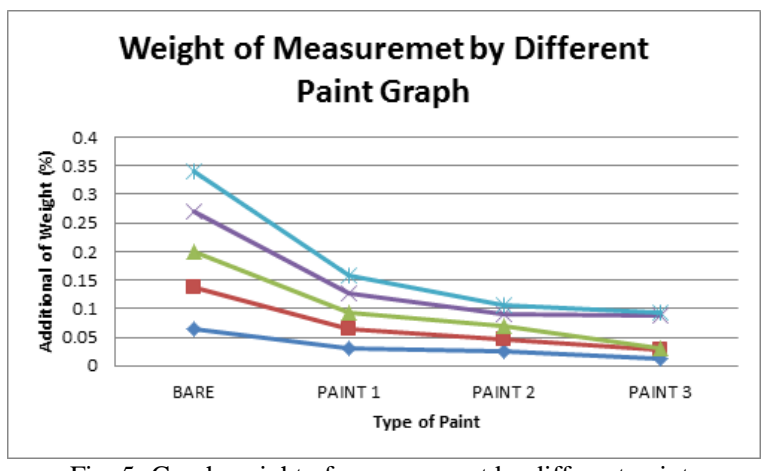

Fig. 5. Graph weight of measurement by different paint.

\section{E. Scanning Electron Microscope (SEM)}

Photograph image for specimens after immersed at Chendering Port is shown in Table VII. Surface of bare mild steel shows many barnacles were attached and it is hardly corroded. Salinity of water contributes a lot in process of attachment of fouling organism. Paint 3 shows lower fouling organisms because it has more concentration of zinc nitrate compare to paint 1 and 2 .

The salinity of sea water at Chendering is constant in range where fouling able to live and attaches to manmade structure. From Dino-Lite image, the quantity fouling organisms are decrease from paint 1 to paint 3 . This shows the positive result of zinc nitrate as antifouling agent.

TABLE VII: SEM AND DINO-LITE AFTER IMMERSION

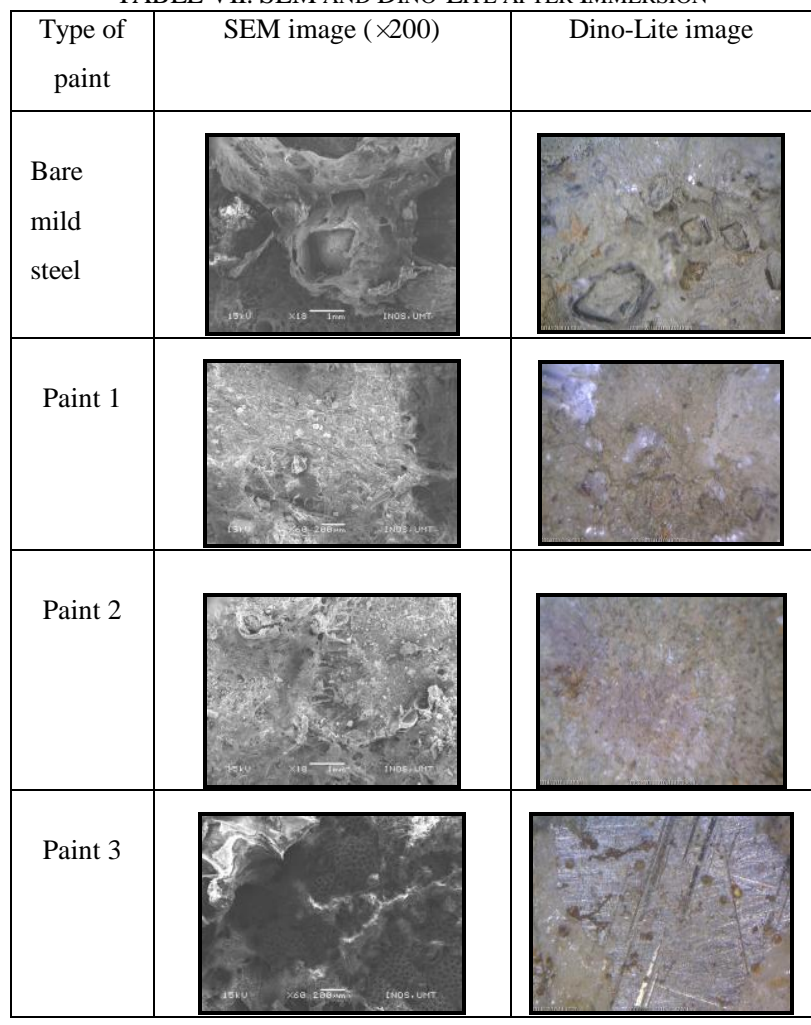

In the absence of zinc nitrate on bare mild steel, there are many barnacles and biofouling attached because lack of protection of mild steel against fouling. There is a little barnacles on surface paint 2 compared to paint 1 . Even though paint 2 is protected by zinc nitrate layer, it seems that the layer is insufficient to protect the mild steel from fouling. Paint 3 shows decrease on biofouling compared to bare, paint 1 and paint 2 because the amount of zinc nitrate is higher.

\section{CONCLUSION}

The objectives of research are achieved by determine and analyses zinc nitrate as antifouling rate, investigate the chemical composition and evaluate antifouling performance of zinc nitrate by using different concentrations. All parameter with presence of zinc nitrate shows biofouling attack by increasing antifouling rate and decreasing the weight gain.

As a conclusion, the higher zinc nitrate used the higher antifouling rate. Zinc nitrate have ability to inhibit the growth and the formation of biofilm of adhesive bacteria. It is significantly prevent the attachment of the biofouling organism.

\section{REFERENCES}

[1] H. Harino, Occurrence and Degradation of Representative TBT-Free Antifouling Biocides in Aquatic Environment, ch. 29, pp. 28-39.

[2] L. F. Melo, T. R. Bott, and C. A. Bernardo, Fouling Science And Technology, Dordrecht, The Netherlands: Kluwer Academic Publishers, 1988.

[3] M. Fingerman, R. Nagabhushanam, and M. F. Thompson, Recent Advances in Marine Biotechnology, Enfield, NH: Science Publishers, Inc, 1999.

[4] J. Walker, S. Surman, and J. Jass, Industrial Biofouling Detection, Prevention and Control, New York, NY: Wiley, 2000.

[5] A. I. Railkin, Marine Biofouling Colonization Processes and Defenses, Boca Raton, FL: CRC Press, 2004.

[6] C. Hellio and D. Yebra, Advances in Marine Antifouling Coatings and Technologies, Boca Raton, FL: CRC Press, 2009.

[7] L. D. Chambers, K. R. Stokes, F. C. Walsh, and R. J. K. Wood, Surface and Coating Technology, 2006, ch. 201, pp. 3642-3652.

[8] N. Bellotti, C. Deya, B. del Amo, and R. Romagnol, Ind. Eng. Chem. Res., 2010, ch. 49, pp. 3386-3390.

[9] C. G. Munger, Corrosion Prevention by Protective Coatings, National Association of Corrosion Engineers, Houston, TX, 1984.

[10] M. Pérez, G. Blustein, M. García, B. del Amo, M. Stupak, Prog. Org. Coat., 2006, ch. 55, p. 311.

[11] K. Schiff, D. Diehl, and A. Valkirs, "Copper emissions from antifouling paint on recreational vessels," Marine Pollut Bull, vol. 48, pp. 371-377, 2004.

[12] D. M. Yebra, S. Kiil, K. Dam-Johansen, and C. Weinell, Prog. Org. Coat., 2005, ch. 53, p. 256.

[13] L. S. Shtykova, D. Ostrovskii, P. Handa, K. Holmberg, and M. Nydén, Prog. Org. Coat., 2004, ch. 51, p. 125.

[14] C. Hellio, C. Simon-Colin, A. S. Clare, and E. Deslandes, Biofouling, 2004, ch. 20, p. 139.

[15] F. Lotgering, Journal of Inorganic and Nuclear Chemistry, vol. 113 1959.

[16] R. Alagarsamy, "Distribution and seasonal variation of trace metal in surface sediments of the mandovi estuary," West Coast of India, Estuarine, Coastal and Shelf Sciences, vol. 67, p. 333, 2006.

[17] S. Kiil et al., J. Coat. Technol., vol. 74, no. 932, p. 89, 2002.

[18] H. A. Rashid, Fuel Science and Technology International, vol. 8, pp 899-916, 1990.

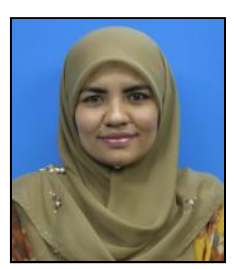

M. J. Suriani is a lecturer at School of Ocean Engineering, University Malaysia Terengganu, Malaysia. She was awarded her $\mathrm{PhD}$ in materials engineering in 2012 from Universiti Putra Malaysia. She has 10 years of teaching experiences and her research interests are composite materials and corrosion.

S. Ramlan is a graduate of Bachelor of Applied Science (Maritime Technology) from Universiti Malaysia Terengganu.

W. B. Wan Nik is a professor of mechanical engineering at the School of Ocean Engineering, University Malaysia Terengganu, Malaysia. 